\title{
ANALISIS KESELAMATAN DAN KESEHATAN KERJA BENGKEL DAN LABORATURIUM JURUSAN PENDIDIKAN TEKNIK ELEKTRONIKA DAN INFORMATIKA FT UNY
}

\author{
Bekti Wulandari \\ Universitas Negeri Yogyakarta \\ E-mail: bektiwulandari@uny.ac.id
}

\begin{abstract}
This research was conducted to describe planning, implementation, and evaluation of Occupational Health and Safety (OHS) in laboratory and workshop of Electronic Engineering and Informatics Department FT UNY. This research is a non-experimental quantitative research with descriptive approach method. Descriptive research is a study conducted on independent variables, without making comparisons or connecting with other variables, especially regarding OHS. This study aims to obtain information or description of $\mathrm{OHS}$ in the laboratory and workshop of Electronic Engineering and Informatics Department, Engineering Faculty, Yogyakarta State University. This research is only limited to describe that found in data retrieval. The results of this study indicate that the OHS System in the laboratory and workshop of Electronic Engineering and Information Technology Department of Engineering Faculty, Yogyakarta State University still needs to be improved. OHS planning in those places still needs to be improved to achieve effectiveness. Meanwhile, the implementation of OHS in the laboratory and workshop still needs to be improved. While the evaluation of OHS in the laboratory and workshop needs to be done continuously. In addition, it can be included that the factors of administration, supervision, and improvement of OHS culture needs to be done in order to achieve a systematic OHS Management System.
\end{abstract}

Keywords: occupational and safety health, OHS culture, OHS management system

\begin{abstract}
ABSTRAK
Penelitian ini dilakukan untuk mendeskripsikan perencanaan, pelaksanaan, dan evaluasi Keselamatan dan Kesehatan Kerja (K3) di laboratorium dan bengkel Jurusan Pendidikan Teknik Elektronika dan Informatika FT UNY. Penelitian ini merupakan penelitian kuantitatif yang bersifat noneksperimental dengan metode pendekatan deskriptif. Penelitian deskriptif adalah penelitian yang dilakukan terhadap variabel mandiri, tanpa membuat perbandingan atau menghubungkan dengan variabel lain khususnya mengenai K3. Penelitian ini bertujuan untuk mendapatkan informasi atau gambaran mengenai K3 di laboratorium dan bengkel Jurusan Pendidikan Teknik Elektronika dan Informatika FT UNY. Penelitian ini hanya sebatas mendeskripsikan yang ditemukan dalam pengambilan data. Hasil penelitian ini menunjukkan bahwa K3 di laboratorium dan bengkel Jurusan Pendidikan Teknik Elektronika dan Informatika FT UNY masih perlu ditingkatkan. Perencanaan K3 di tempat-tempat tersebut masih perlu ditingkatkan untuk mencapai keefektifan. Sementara itu, pelaksanaan K3 di laboratorium dan bengkel masih perlu ditingkatkan. Sedangkan evaluasi K3 di laboratorium dan bengkel perlu dilakukan secara terus menerus. Selain itu dapat disertakan pula bahwa faktor administrasi, pengawasan, dan peningkatan budaya K3 perlu dilakukan guna tercapainya Sistem Manajemen K3 yang sistematis.
\end{abstract}

Kata kunci: keselamatan dan kesehatan kerja (K3), budaya K3, sistem manajemen K3

\section{PENDAHULUAN}

Keselamatan dan Kesehatan Kerja yang sering disingkat dengan K3 merupakan bagian penting dari suatu upaya untuk meningkatkan kualitas kinerja orang di tempat kerja. Hal ini ditunjukkan dengan masih tingginya tingkat kecelakaan kerja yang ada di Indonesia. Data dari Badan Pusat Statistik (BPS) menyebutkan bahwa jumlah kasus kecelakaan akibat kerja yang terjadi di tempat kerja baik di industri atau di sekolah tahun 2011-2014 yang paling tinggi pada 2013 yaitu 35.917 kasus kecelakaan kerja $($ Tahun $2011=9.891$; 
Tahun $2012=21.735 ;$ Tahun $2014=$ 24.910). Walaupun K3 memiliki dasar hukum yang kuat dalam Undang-Undang, tetapi penerapan $\mathrm{K} 3$ dalam tempat kerja memang belum terlaksana dengan baik secara menyeluruh. Salah satu contohnya adalah Seorang siswa SMK Maarif, Nanggulan, Kulonprogo, Provinsi DIY, Agus Nugroho dan gurunya terbakar saat sedang praktik mengelas di sekolahnya ${ }^{(1)}$.

Sebenarnya pemilik tempat kerja dalam hal ini sekolah maupun perguruan tinggi bisa mencegah kecelakaan tersebut, jika saja dapat memberikan pelayanan $\mathrm{K} 3$ yang baik terhadap pekerja serta memberi jaminan atas kecelakaan tersebut, sehingga para pekerja merasa aman, nyaman dan terlindungi dengan adanya program $\mathrm{K} 3$ yang terlaksana di tempat kerja tersebut. Semua pekerjaan, baik itu di laboratorium, bengkel, maupun perusahaan selalu akan ada resiko kecelakaan pada suatu aktifitas pekerjaan, baik itu disebabkan perencanaan, pelaksanaan, maupun akibat yang tidak disengaja. Semua resiko tersebut akan mengakibatkan kerugian pada saat terjadinya kecelakaan kerja. Oleh karena itu, kecelakaan kerja harus diminimalisir, apabila memungkinan maka dihilangkan, atau setidak-tidaknya dikurangi dampaknya.

Penanganan masalah K3 di tempat kerja harus dilakukan secara menyeluruh termasuk di dalam bengkel maupun laboratorium di suatu lembaga pendidikan. Lembaga pendidikan seperti di lingkungan Jurusan Pendidikan Teknik Elektronika dan Informatika FT UNY memiliki bengkel dan laboratorium sebagai tempat praktik yang juga harus menerapkan K3. Jumlah bengkel dan laboraturium yang ada di jurusan Pendidikan Teknik Elektronika dan Informatika sebanyak 9, sehingga semua sivitas akademika (dosen, teknisi, dan mahasiswa) yang terlibat di bengkel dan laboratorium harus ikut menjaga keselamatan dan kesehatan kerja. Penerapan K3 tidak hanya pemasangan spanduk, poster, dan semboyan tetapi harus jauh dari itu, K3 harus menjadi "hati" pada setiap pekerja yang berada di tempat kerja. Akan tetapi pekerja yang dimaksud dalam penelitian ini adalah dosen, teknisi, dan mahasiswa.

Banyak terjadi kelalaian terhadap bahaya yang mengancam hanya karena alasan efisiensi kerja, misalnya pemakaian alat atau bahan yang tidak memenuhi syarat tapi dipaksakan untuk dipakai. Upaya optimalisasi sangat diperlukan, tetapi harus memenuhi syarat keselamatan dan kesehatan kerja. Padahal sebenarnya biaya yang dikeluarkan apabila terjadi kecelakaan sangat jauh lebih besar dari pada pencegahannya. Pada dasarnya sistem manajemen keselamatan dan kesehatan kerja perlu direncanakan, dijalankan serta dievaluasi sebaik mungkin. Perencanaan tersebut hendaknya disusun berdasar keadaan sebenarnya yang ada di tempat kerja.

Keadaan ruang bengkel dan laboratorium serta semua peralatan di dalamnya harus diidentifikasi potensi bahaya yang dapat ditimbulkan. Selain itu, pelaksanaan K3 harus dilakukan sesuai rencana yang telah disusun. Pelaksanaan tersebut hendaknya dilakukan oleh semua pihak sivitas akademika yang terlibat di tempat kerja. Apabila pelaksanaan telah sesuai dengan yang telah direncanakan, maka potensi rugi akibat kecelakaan kerja akan dapat dikurangi dan bahkan dihilangkan. Tahapan dari sistem manajemen K3 yang selanjutnya dilakukan adalah evaluasi. Proses ini hendaknya rutin dilakukan secara bertahap dan terus menerus tiap semester berlangsung. Evaluasi ini diharapkan dapat mengetahui kekurangan dari pelaksanaan $\mathrm{K}$ 3, sehingga dapat disusun perencanaan yang lebih baik. Penelitian ini bertujuan untuk 
mendeskripsikan perencanaan keselamatan dan kesehatan kerja di tempat kerja (laboratorium dan bengkel) Jurusan Pendidikan Teknik Elektronika dan Informatika FT UNY, pelaksanaan keselamatan dan kesehatan kerja di tempat kerja (laboratorium dan bengkel) Jurusan Pendidikan Teknik Elektronika dan Informatika FT UNY, evaluasi K3 keselamatan dan kesehatan kerja di tempat kerja (laboratorium dan bengkel) Jurusan Pendidikan Teknik Elektronika dan Informatika FT UNY

Filosofi dasar Keselamatan dan Kesehatan Kerja (K3) adalah melindungi keselamatan dan kesehatan para pekerja dalam menjalankan pekerjaannya, melalui upaya-upaya pengendalian semua bentuk potensi bahaya yang ada di lingkungan tempat kerjanya. Bila semua potensi bahaya telah dikendalikan dan memenuhi batas standar aman, maka akan memberikan kontribusi terciptanya kondisi lingkungan kerja yang aman, sehat, dan proses produksi menjadi lancar, yang pada akhirnya akan dapat menekan risiko kerugian dan berdampak terhadap peningkatan produktivitas. Menurut International Association of Safety Professional (2), Filosofi K3 terbagi menjadi 8 filosofi yaitu: (1) Safety is an ethical responsibility. K3 adalah tanggung jawab moral/etik. Masalah K3 hendaklah menjadi tanggung awab moral untuk menjaga keselamatan sesama manusia. K3 bukan sekedar pemenuhan perundangan atau kewajiban; (2) Safety is a culture, not a program. K3 bukan sekedar program yang dijalankan perusahaan untuk sekedar memperoleh penghargaan dan sertifikat. K3 hendaklah menjadi cerminan dari budaya dalam organisasi. (3) Management is responsible. Manajemen perusahaan adalah yang paling bertanggung jawab mengenai K3. Sebagian tanggung jawab dapat dilimpahkan secara beruntun ke tingkat yang lebih bawah; (4) Employee must be trained to work safety. Setiap tempat kerja, lingkungan kerja, dan jenis pekerjaan memiliki karakteristik dan persyaratan K3 yang berbeda. K3 harus ditanamkan dan dibangun melalui pembinaan dan pelatihan; (5) Safety is a condition of employment. Tempat kerja yang baik adalah tempat kerja yang aman. Lingkungan kerja yang menyenangkan dan serasi akan mendukung tingkat keselamatan. Kondisi K3 dalam perusahaan adalah pencerminan dari kondisi ketenagakerjaan dalam perusahaan; (6) All injuries are preventable. Prinsip dasar dari K3 adalah semua kecelakaan dapat dicegah karena kecelakaan ada sebabnya. Jika sebab kecelakaan dapat dihilangkan maka kemungkinan kecelakaan dapat dihindarkan; (7) Safety program must be site specific. Program K3 harus dibuat berdasarkan kebutuhan kondisi dan kebutuhan nyata di tempat kerja sesuai dengan potensi bahaya sifat kegiatan, kultur, kemampuan finansial, dll. Program K3 dirancang spesifik untuk masing-masing organisasi atau perusahaan; dan (8) Safety is good business. Melaksanakan K3 jangan dianggap sebagai pemborosan atau biaya tambahan. Melaksanakan K3 adalah sebagai bagian dari proses produksi atau strategi perusahaan. Kinerja K3 yang baik akan memberikan manfaat terhadap bisnis perusahaan.

Keselamatan dan kesehatan kerja dapat diartikan sebagai sebuah pemikiran dan upaya untuk menjamin keutuhan dan kesempurnaan: tenaga kerja dan manusia pada umumnya (baik jasmani maupun rohani), hasil karya dan budaya menuju masyarakat adil, makmur dansejahtera. Sedangkan ditinjau dari keilmuan, keselamatan dan kesehatan kerja diartikan sebagai suatu ilmu pengetahuan dan penerapannya dalam upaya mencegah kecelakaan, kebakaran, peledakan, pencemaran, penyakit, dan sebagainya.

Keselamatan dan kesehatan kerja merupakan hal yang penting dan harus 
mendapatkan perhatian serius. Perhatian dunia internasional terhadap keselamatan dan kesehatan kerja semakin tinggi sejak lahirnya Occupational and Safety Management Systems atau sering disingkat dengan OHSAS 18001: 1999 diterbitkan oleh British Standard International (BSI) dan badan-badan sertifikasi dunia yang berisi standar manajemen $\mathrm{K} 3{ }^{(3)}$. Indonesia juga memiliki perhatian serius terhadap keselamatan dan kesehatan kerja. Hal ini dibuktikan dengan diterbitkannya beberapa aturan yang terkait dengan keselamatan dan kesehatan kerja. Undang-undang yang terkait dengan K3 diantaranya adalah Undang-Undang No 1 Tahun 1970 tentang Keselamatan Kerja ${ }^{(4)}$ dan Undang-Undang Republik Indonesia No 13 Tahun 2003 tentang Ketenagakerjaan ${ }^{(5)}$. Selanjutnya, tujuan utama dalam Penerapan K3 berdasarkan Undang-Undang No. 1 Tahun 1970 tentang Keselamatan Kerja yaitu adalah melindungi dan menjamin keselamatan setiap tenaga kerja dan orang lain di tempat kerja, menjamin setiap sumber produksi dapat digunakan secara aman dan efisien, dan meningkatkan kesejahteraan dan produktivitas nasional.

\section{METODE}

Penelitian ini adalah penelitian kuantitatif yang bersifat non-eksperimental dengan metode pendekatan deskriptif. Penelitian deskriptif adalah penelitian yang dilakukan terhadap variabel mandiri, tanpa membuat perbandingan atau menghubungkan dengan variabel lain. Penelitian deskriptif ini bertujuan untuk mendapatkan informasi atau gambaran mengenai keselamatan dan kesehatan kerja (K3) di jurusan Pendidikan Teknik Elektronika dan Informatika FT UNY. Penelitian ini dilaksanakan di bengkel dan laboraturium jurusan Pendidikan Teknik Elektronika dan Informatika Fakultas
Teknik UNY. Penelitian ini dilaksanakan pada bulan April sampai Oktober 2017.

Metode pengumpulan data dalam penelitian ini menggunakan observasi, wawancara, dan angket. Observasi dilakukan langsung ke bengkel-bengkel yang ada di Jurusan Teknik Elektronika dan Informatika FT UNY. Wawancara dilakukan dengan dosen maupun teknisi untuk memperoleh data pendukung penelitian. Selain itu, data dari angket mengenai K3 diberikan kepada responden. Data tersebut menggunakan skala Likert.

Instrumen penelitian ini dibuat dalam bentuk instrumen sesuai dengan jenis data yang diungkap yaitu berupa lembar observasi, angket tebuka dan angket tertutup. Angket terbuka ini memuat sejumlah pertanyaan yang jawabannya dapat diisi sesuai dengan kehendak dan keadaan responden. Sedangkan angket tertutup disajikan dalam bentuk sedemikan rupa sehingga responden dapat memilih satu jawaban yang sesuai dengan memberikan tanda checklist. Instrument disusun berdasarkan kisi-kisi yang dinyatakan oleh Ridley ${ }^{(6)}$ dengan indikator diantaranya adalah sebagai berikut: (1) Faktor perencanaan dengan indikator komitmen terhadap K3; (2) Faktor pelaksanaan dengan indikator emliputi komunikasi, kompetensi, lingkungan kerja, peralatan, keterlibatan mahasiswa dan teknisi; (3) Faktor evaluasi dengan indikator meliputi program penilaian resiko, identifikasi bahaya dan strategi pencegahan. Sedangkan indikator pada observasi adalah kegiatan, bahaya, potential insiden, risk rangking, pengendalian bahaya dan insiden.

Teknik analisis yang digunakan adalah teknik analisis deskriptif kuantitatif. Berdasarkan data hasil penelitian yang telah terkumpul maka diskripsi data yang disajikan pada penelitian meliputi rerata, persentase, dan diagram batang dari setiap instrumen variabel penelitian. Rerata yang diperoleh setiap indikator kemudian 
dikonversikan menjadi nilai, pada skala 5, dengan acuan yang dikutip dari Sukardjo ${ }^{(7)}$ seperti pada Tabel 1.

Tabel 1. Konversi Skor Ke Nilai pada Skala 5

\begin{tabular}{lcl}
\hline \multicolumn{1}{c}{ Interval Skor } & Nilai & \multicolumn{1}{c}{ Kategori } \\
\hline $\mathrm{X}>M i+1,8 \mathrm{Sbi}$ & $\mathrm{A}$ & Sangat Baik \\
$M i+0,6 S B i<\mathrm{X} \leq M i$ & $\mathrm{~B}$ & Baik \\
$+1,8 \mathrm{Sbi}$ & & \\
$M i-0,6 S B i<\mathrm{X} \leq M i$ & $\mathrm{C}$ & Cukup Baik \\
$+0,6 \mathrm{Sbi}$ & & \\
$M i-1,8 \mathrm{SBi}<\mathrm{X} \leq M i$ & $\mathrm{D}$ & Kurang Baik \\
$-0,6 S B i$ & & \\
$\mathrm{X} \leq M i-1,8 S B i$ & $\mathrm{E}$ & $\begin{array}{l}\text { Sangat } \\
\text { Kurang Baik }\end{array}$ \\
\hline
\end{tabular}

dengan keterangan;

$\mathrm{X}=$ skor aktual (empiris)

$M i=$ mean ideal, dihitung dengan menggunakan rumus: $M i=1 / 2$ \{skor maksimal ideal + skor minimal ideal\} (1)

$S B i=$ simpangan baku ideal, ditentukan dengan rumus: $S B i=1 / 6$ skor maksimal ideal skor minimal ideal\}

Dari skala 5 tersebut di atas diketahui bahwa skor maksimal ideal adalah 5 dan skor minimal ideal adalah 1, sehingga diperoleh perhitungan $M i=1 / 2(5+1)=3$ dan $S B i=1 / 6(5-1)=0,67$. Berdasarkan ketentuan tersebut, diperoleh hasil perhitungan skala 5 sebagaimana dapat dilihat pada Tabel 2.

Tabel 2. Konversi Data Kualitatif Menjadi Data Kuantitatif (Skala 5)

\begin{tabular}{clcc}
\hline Skala & \multirow{2}{*}{ Kriteria } & $\begin{array}{c}\text { Skor } \\
\text { Perhitungan }\end{array}$ & Hasil \\
\hline 5 & Sangat & $\mathrm{X}>3+(1,8 \mathrm{x}$ & $\mathrm{X}>4,2$ \\
& Baik & $0,67)$ & \\
4 & Baik & $3+(0,6 \mathrm{x} 0,67)$ & $3,4<\mathrm{X}$ \\
& & $<\mathrm{X} \leq 3+$ & $\leq 4,2$ \\
& & $(1,8 \times 0,67)$ & \\
3 & Cukup & $3-(0,6 \times 0,67)$ & $2,6<\mathrm{X}$ \\
& & $<\mathrm{X} \leq 3+$ & $\leq 3,4$ \\
& & $(0,6 \times 0,67)$ & \\
2 & Kurang & $3-(1,8 \times 0,67)$ & $1,8<\mathrm{X}$ \\
& & $<\mathrm{X} \leq 3-$ & $\leq 2,6$ \\
& & $(0,6 \times 0,67)$ & \\
1 & Sangat & $\mathrm{X} \leq 3-$ & $\mathrm{X} \leq 1,8$ \\
& Kurang & $(1,8 \times 0,67)$ & \\
\hline
\end{tabular}

Untuk memperkuat data yang diperoleh dari observasi dan angket terbuka digunakan teknik analisis kualitatif dengan cara reduksi data, penyajian data, dan verifikasi data.

\section{HASIL DAN PEMBAHASAN}

Observasi dilakukan oleh peneliti secara langsung di bengkel dan laboraturium Pendidikan Teknik Elektronika dan Informatika FT UNY, yaitu di Lab. Telekomunikasi, Lab. FTTH, Lab. Komputer Dasar, Lab. RF, Ruang Bengkel, Lab. Kendali, dan Lab. TV. Selain itu, peneliti juga melakukan wawancara dengan teknisi masing-masing bengkel dan laboraturium tersebut. Hasil dari observasi di Lab telekomunikasi ditemui penyimpanan dan penangan alat yag kurang rapi. Hal ini dapat mengurangi kenyamanan saat praktikum. Meskipun dalam Lab ini ditemukan APAR, akan tetapi tidak ditemukan kotak P3K sehingga pada saat praktikum terjadi kecelakaaan kerja tidak bisa langsung diobati.

Tingkat bahaya di laboraturium komputer tergolong rendah apabila dibandingkan dengan laboraturium yang lainnya karena penempatan kabel sudah rapi dan sudah dilindungi. Akan tetapi dalam laboraturium ini, ditemukan mahasiswa pada saat praktik tidak memperhatikan cara duduknya, sedangkan ergonomi sudah di desain dalam laboraturium ini.

Bengkel elektronika mempunyai potensi bahaya paling besar karena ada penggunaan bahan kimia seperti $\mathrm{HCl}$ sehingga perlu diperhatikan pengendalian bahan kimia agar tidak mengganggu aktivitas kerja praktik. Di semua laboraturium, kondidi penerangan sudah baik dimana pada saat praktikum semua lampu dinyalakan.

Hasil perhitungan pada masingmasing indikator setiap faktor di Lab Telekomunikasi, FTTH, Komputer Dasar, RF, Ruang Bengkel, Lab Kendali, dan Lab TV diatas dibuat Tabel 3. 
Tabel 3. Kategori Penilaian Indikator pada setiap laboratorium dan bengkel

\begin{tabular}{|c|c|c|c|c|c|c|c|c|}
\hline No & Indikator & $\begin{array}{l}\text { Lab } \\
\text { Telekom } \\
\text { unikasi }\end{array}$ & FTTH & $\begin{array}{l}\text { Komputer } \\
\text { Dasar }\end{array}$ & $\mathrm{RF}$ & $\begin{array}{l}\text { Ruang } \\
\text { Bengkel }\end{array}$ & $\begin{array}{l}\text { Lab } \\
\text { Kendali }\end{array}$ & Lab TV \\
\hline 1 & $\begin{array}{l}\text { Komitmen } \\
\text { terhadap K3 }\end{array}$ & $\begin{array}{l}\text { Cukup } \\
\text { baik }\end{array}$ & $\begin{array}{l}\text { Cukup } \\
\text { baik }\end{array}$ & $\begin{array}{l}\text { Cukup } \\
\text { baik }\end{array}$ & $\begin{array}{l}\text { Cukup } \\
\text { baik }\end{array}$ & $\begin{array}{l}\text { Cukup } \\
\text { baik }\end{array}$ & $\begin{array}{l}\text { Cukup } \\
\text { baik }\end{array}$ & Baik \\
\hline 2 & $\begin{array}{l}\text { Identifikasi } \\
\text { Bahaya }\end{array}$ & $\begin{array}{l}\text { Cukup } \\
\text { baik }\end{array}$ & $\begin{array}{l}\text { Cukup } \\
\text { baik }\end{array}$ & Baik & $\begin{array}{l}\text { Cukup } \\
\text { baik }\end{array}$ & $\begin{array}{l}\text { Cukup } \\
\text { baik }\end{array}$ & Baik & Baik \\
\hline 3 & $\begin{array}{l}\text { Strategi } \\
\text { Pencegahan }\end{array}$ & Baik & $\begin{array}{l}\text { Cukup } \\
\text { baik }\end{array}$ & Baik & $\begin{array}{l}\text { Cukup } \\
\text { baik }\end{array}$ & $\begin{array}{l}\text { Cukup } \\
\text { baik }\end{array}$ & Baik & Baik \\
\hline 4 & $\begin{array}{l}\text { Keterlibatan } \\
\text { Teknisi dan } \\
\text { Mahasiswa }\end{array}$ & Baik & $\begin{array}{l}\text { Cukup } \\
\text { baik }\end{array}$ & Baik & $\begin{array}{l}\text { Cukup } \\
\text { baik }\end{array}$ & $\begin{array}{l}\text { Cukup } \\
\text { baik }\end{array}$ & Baik & Baik \\
\hline 5 & $\begin{array}{l}\text { Lingkungan } \\
\text { Kerja }\end{array}$ & $\begin{array}{l}\text { Cukup } \\
\text { baik }\end{array}$ & $\begin{array}{l}\text { Sangat } \\
\text { baik }\end{array}$ & Baik & Baik & Baik & Baik & $\begin{array}{l}\text { Sangat } \\
\text { baik }\end{array}$ \\
\hline 6 & Komunikasi & $\begin{array}{l}\text { Cukup } \\
\text { baik }\end{array}$ & $\begin{array}{l}\text { Cukup } \\
\text { baik }\end{array}$ & $\begin{array}{l}\text { Cukup } \\
\text { baik }\end{array}$ & $\begin{array}{l}\text { Cukup } \\
\text { baik }\end{array}$ & $\begin{array}{l}\text { Cukup } \\
\text { baik }\end{array}$ & $\begin{array}{l}\text { Cukup } \\
\text { baik }\end{array}$ & $\begin{array}{l}\text { Cukup } \\
\text { baik }\end{array}$ \\
\hline 7 & Kompetensi & $\begin{array}{l}\text { Cukup } \\
\text { baik }\end{array}$ & Baik & Baik & Baik & Baik & Baik & Baik \\
\hline 8 & Peralatan & $\begin{array}{l}\text { Cukup } \\
\text { baik }\end{array}$ & $\begin{array}{l}\text { Cukup } \\
\text { baik }\end{array}$ & Baik & $\begin{array}{l}\text { Cukup } \\
\text { baik }\end{array}$ & $\begin{array}{l}\text { Cukup } \\
\text { baik }\end{array}$ & $\begin{array}{l}\text { Cukup } \\
\text { baik }\end{array}$ & $\begin{array}{l}\text { Cukup } \\
\text { baik }\end{array}$ \\
\hline 9 & $\begin{array}{l}\text { Program } \\
\text { Penilaian } \\
\text { Resiko }\end{array}$ & $\begin{array}{l}\text { Cukup } \\
\text { baik }\end{array}$ & $\begin{array}{l}\text { Cukup } \\
\text { baik }\end{array}$ & $\begin{array}{l}\text { Cukup } \\
\text { baik }\end{array}$ & $\begin{array}{l}\text { Cukup } \\
\text { baik }\end{array}$ & $\begin{array}{l}\text { Kurang } \\
\text { baik }\end{array}$ & $\begin{array}{l}\text { Cukup } \\
\text { baik }\end{array}$ & Baik \\
\hline
\end{tabular}

Hasil penelitian menunjukkan bahwa Keselamatan dan Kesehatan Kerja (K3) di Lab Telekomunikasi, FTTH, Komputer Dasar, RF, Ruang Bengkel, Lab Kendali, Lab TV Jurusan Pendidikan Teknik Elektronika dan Informatika FT UNY masih perlu ditingkatkan. Bisa dikatakan demikian karena masih banyak terdapat potensi bahaya yang ada di laboratorium dan bengkel tersebut, hal ini seharusnya bisa diminimalisir sebaik mungkin karena hal ini sangat penting bagi keberlanjutan sistem K3 di lab laboratorium dan bengkel tersebut. Hal ini tidak lepas dari kesadaran dari semua pengguna tempat-tempat tersebut demi keberlangsungan kerja yang aman dan nyaman.

Bengkel menjadi tempat yang paling besar adanya potensi bahaya karena di tempat tersebut paling banyak alat-alat dan bahan yang sangat besar berpotensi menjadi kecelakaan bagi pengguna bengkel tersebut dan bahkan orang-orang yang ada disekitar tempat orang-orang bekerja. Ini terbukti bahwa dari sembilan indikator yang sudah diisi oleh pengguna hanya dua yang mendapatkan penilaian baik dan bahkan ada satu indikator yang bernilai kurang baik di dalam bengkel tersebut yaitu indikator program penilaian resiko.

Sementara itu, Lab TV menjadi tempat yang paling baik dalam menjalankan sistem K3, ini terbukti dari Sembilan indikator yang sudah diisi oleh pengguna laboratorium tersebut mendapatkan enam penilaian baik dan bahkan ada satu indikator yang bernilai sangat baik yaitu lingkungan kerja.

Aplikasi sistem K3 diperlukan usaha yang terencana dan efektif. Semua pengguna laboratorium dan bengkel tersebut perlu mengaplikasikan budaya K3 dalam praktik sehari-hari khususnya dalam bekerja di areaarea tersebut. Diperlukan kebijakan untuk menerapkan K3 untuk area-area kerja tersebut. Larangan, peraturan dan tata tertib harus selalu diterapkan, diawasi dan dievaluasi dengan perencanaan yang efektif sehingga para pengguna area-area tersebut merasa aman dan nyaman dalam bekerja. Dosen dan teknisi hendaknya selalu mengingatkan mahasiswa agar dalam bekerja selalu memperhatikan faktor K3 dan member tauladan bagi mahasiswa- 
mahasiswa yang sedang belajar dan bekerja di area-area tersebut. Terutama penggunaan alat pelindung diri (APD).

Bekerja harus sesuai dengan Standard Operating Procedure (SOP) karena potensi kecelakaan kerja selalu ada dalam setiap area dan pekerjaan baik itu kelalaian manusia maupun faktor dari mesin atau bahan yang digunakan. Untuk itu seharusnya setiap pekerjaan di laboratorium dan bengkel tersebut harus ada SOP yang sudah divalidasi oleh atasan terutama yang sudah ahli dalam K3.

Pengawasan oleh dosen, instruktur, maupun teknisi penting dilakukan, karena mahasiswa terkadang bekerja tidak sesuai SOP bila tidak ada yang mengawasi pekerjaan mereka. Hal ini sangat bagus untuk meminimalisir terjadinya kecelakaan kerja baik itu dari mahasiswa ataupun orang0orang yang berada disekitar mahasiswa tersebut.

Rekaman-rekaman kecelakaan seharusnya didokumentasikan dengan baik, karena ini sangat penting untuk dijadikan pengalaman bagi para praktikan yang sedang bekerja di area-area tersebut untuk meminimalisir terjadinya kecelakaan. Bisa berupa papan-papan peringatan maupun video yang bisa dilihat kapan saja untuk pembelajaran bagi semua pengguna tempattempat tersebut.

\section{SIMPULAN}

Berdasarkan pembahasan dan hasil perolehan data dalam penelitian ini dapat disimpulkan bahwa budaya Keselamatan dan Kesehatan Kerja (K3) di Lab Telekomunikasi, FTTH, Komputer Dasar, RF, Ruang Bengkel, Lab Kendali, Lab TV Jurusan Pendidikan Teknik Elektronika dan Informatika FT UNY masih perlu ditingkatkan. Hal tersebut sangat terkait dengan penentuan kebijakan K3 sehingga dapat diaplikasikan dalam pekerjaanpekerjaan di tempat tersebut.
Perencanaan K3 di Lab Telekomunikasi, FTTH, Komputer Dasar, RF, Ruang Bengkel, Lab Kendali, Lab TV Jurusan Pendidikan Teknik Elektronika dan Informatika FT UNY masih perlu dibenahi untuk mendapatkan penerapan K3 yang maksimal. Hal tersebut sangat penting karena banyak adanya potensi bahaya yang timbul akibat situasi dan kondisi laboratorium dan bengkel saat ini.

$$
\text { Pelaksanaan K3 di Lab }
$$

Telekomunikasi, FTTH, Komputer Dasar, RF, Ruang Bengkel, Lab Kendali, Lab TV Jurusan Pendidikan Teknik Elektronika dan Informatika FT UNY masih perlu ditingkatkan. Hal ini disebabkan oleh perencanaan yang belum baik sehingga harus direncanakan sebelumnya dengan baik dan sistematis.

Evaluasi K3 di Lab Telekomunikasi, FTTH, Komputer Dasar, RF, Ruang Bengkel, Lab Kendali, Lab TV Jurusan Pendidikan Teknik Elektronika dan Informatika FT UNY perlu dilakukan secara terus menerus berdasarkan kesepakatan dari atasan-atasan yang terkait dengan tempattempat tersebut. Pengawasan dan evaluasi harus selalu dilakukan oleh pihak penentu kebijakan, dosen, dan teknisi yang mempunyai kompetensi dalam sistem K3.

\section{REFERENSI}

[1] Kuntadi. Berita DIY: Praktik Mengelas, Siswa dan Guru Terbakar. sindonews.com. [Online] 2017. [Cited: November 10, 2017.] https://daerah.sindonews.com/read/125 5032/189/praktik-mengelas-siswa-danguru-terbakar-1509972107.

[2] Soehetman, Ramli. Sistem Manajemen Keselamatan \& Kesehatan Kerja OHSAS $18001 \quad$ (husyain Djajaningrat.ed). Seri Manajemen K301. Cetakan ke3. Jakarta: PT. Dian Rakyat, 2013. 
[3] 18001, OHSAS. Sistem Manajemen Keselamatan Dan Kesehatan Kerja. 2007.

[4] Indonesia, Republik. UU Nomor 1 Tahun 1970 tentang Keselamatan Kerja. Jakarta: Kementerian Sekretariat Negara Republik Indonesia, 1970.

[5] Indonesia, Republik. Undang-undang Republik Indonesia Nomor 13 Tahun 2003 tentang Ketenagakerjaan. Jakarta: Sekretaris Negara Republik Indonesia, 2003.

[6] Ridley, John. Kesehatan dan Keselamatan Kerja. Yogyakarta: Erlangga, 2004.

[7] Sukardjo. Desain pembelajaran: Evaluasi pembelajaran. Yogyakarta: Handout perkuliahan: Program Pascasarjana Universitas Negeri Yogyakarta, 2005 